\title{
Effect of altering breathing frequency on maximum voluntary ventilation in healthy adults
}

\author{
Eric V. Neufeld ${ }^{1}$, Brett A. Dolezal ${ }^{1 *}$, William Speier ${ }^{2}$ and Christopher B. Cooper ${ }^{1}$
}

\begin{abstract}
Background: Compared to other pulmonary function tests, there is a lack of standardization regarding how a maximum voluntary ventilation (MW) maneuver is performed. Specifically, little is known about the variation in breathing frequency $\left(f_{R}\right)$ and its potential impact on the accuracy of test results. This study examines the effect of several preselected values for $f_{R}$ and one self-selected $f_{R}\left(f_{\text {Rself }}\right)$ on MW.

Methods: Ten participants performed MW maneuvers at various $f_{\mathrm{R}}$ values, ranging from 50 to 130 breaths. $\mathrm{min}^{-1}$ in 10 breaths. $\mathrm{min}^{-1}$ intervals and at one $f_{\text {Rself. }}$. Three identical trials with 2-min rest periods were conducted at each $f_{R}$, and the sequence in which $f_{R}$ was tested was randomized. Ventilation and related parameters were measured directly by gas exchange analysis via a metabolic measurement system.

Results: A third-order polynomial regression analysis showed that MW $=-0.0001\left(f_{R}\right)^{3}+0.0258\left(f_{R}\right)^{2}-1.38\left(f_{R}\right)+96.9$ at preselected $f_{R}$ and increased up to approximately 100 breaths $\min ^{-1}\left(r^{2}=0.982, P<0.001\right)$. Paired $t$-tests indicated that average MW values obtained at all preselected $f_{R}$ values, but not $f_{\text {Rself, }}$ were significantly lower than the average maximum value across all participants. A linear regression analysis revealed that tidal volume $\left(V_{T}\right)=-2.63(\mathrm{MW})+300.4$ at preselected $f_{R}\left(r^{2}=0.846, P<0.001\right)$; however, this inverse relationship between $V_{T}$ and $M W$ did not remain true for the self-selected $f_{R}$. The $V_{T}$ obtained at this $f_{R}\left(90.9 \pm 19.1 \%\right.$ of maximum) was significantly greater than the $V_{T}$ associated with the most similar MV value (at a preselected $f_{\mathrm{R}}$ of 100 breaths. min $^{-1}, 62.0 \pm 10.4 \%$ of maximum; 95\% confidence interval of difference: $(17.5,40.4 \%), P<0.001)$.

Conclusions: This study demonstrates the shortcomings of the current lack of standardization in MW testing and establishes data-driven recommendations for optimal $f_{R}$. The true MW was obtained with a self-selected $f_{\mathrm{R}}$ (mean $\pm \mathrm{SD}: 69.9 \pm 22.3$ breaths $\cdot \mathrm{min}^{-1}$ ) or within a preselected $f_{\mathrm{R}}$ range of $110-120$ breaths. $\mathrm{min}^{-1}$. Until a comprehensive reference equation is established, it is advised that MV be measured directly using these guidelines. If an individual is unable to perform or performs the maneuver poorly at a self-selected $f_{R}$, ventilating within a mandated $f_{\mathrm{R}}$ range of $110-120$ breaths: $\mathrm{min}^{-1}$ may also be acceptable.
\end{abstract}

Keywords: Pulmonary function test, Standardization, Breathing frequency, Exercise testing, Ventilatory reserve, Maximal exercise ventilation, Forced expiratory volume in $1 \mathrm{~s}$

\footnotetext{
* Correspondence: BDolezal@mednet.ucla.edu

'Exercise Physiology Research Laboratory, Departments of Medicine and

Physiology, David Geffen School of Medicine at UCLA, 10833 Le Conte

Avenue, 37-131 CHS Building, Los Angeles, CA 90095, USA

Full list of author information is available at the end of the article
}

(c) The Author(s). 2018 Open Access This article is distributed under the terms of the Creative Commons Attribution 4.0 International License (http://creativecommons.org/licenses/by/4.0/), which permits unrestricted use, distribution, and reproduction in any medium, provided you give appropriate credit to the original author(s) and the source, provide a link to the Creative Commons license, and indicate if changes were made. The Creative Commons Public Domain Dedication waiver (http://creativecommons.org/publicdomain/zero/1.0/) applies to the data made available in this article, unless otherwise stated. 


\section{Background}

Formerly referred to as maximum breathing capacity, maximum voluntary ventilation (MVV) is a pulmonary function test (PFT) that measures the maximum amount of air a person can inhale and then exhale with voluntary effort. The test is measured in liters per minute $\left(\mathrm{L} \cdot \mathrm{min}^{-1}\right)$, but data is only collected for $12-15 \mathrm{~s}$ and then extrapolated to $1 \mathrm{~m}$ in order avoid prolonged hyperventilation by the participant. While the test has been used less over the recent decades due to its fewer applications than the forced expiratory volume in $1 \mathrm{~s}\left(\mathrm{FEV}_{1}\right)$, MVV still possesses clinical utility. Performing the maneuver is contingent on several factors, including respiratory system mechanics (obstructive or restrictive) and ventilatory muscle endurance. Therefore, the test provides a broad assessment of respiratory system function [1]. Abnormal MVV results are valuable in evaluating various neuromuscular disorders [2-4] and predicting the risk for postoperative complications $[1,5]$. MVV also remains useful in cardiopulmonary exercise testing as a measure of ventilatory capacity, especially in determining an individual's ventilatory reserve-the difference between MVV and maximal exercise ventilation $\left(\dot{V}_{E \max }\right)$-which aids in the diagnosis and differentiation of pulmonary and cardiovascular diseases [6-10].

What primarily distinguishes MVV from other PFTs, however, is the lack of standardization regarding how the maneuver is performed. A major component of the test is breathing frequency $\left(f_{\mathrm{R}}\right)$, but little consensus exists on precisely what $f_{\mathrm{R}}$ or range of $f_{\mathrm{R}}$ values yield optimal results. The majority of both past and current research that employed MVV does not provide the frequency at which participants ventilated as part of the methodology [11-13]. Moreover, the few studies that do provide this information offer diverging suggestions. One of the earliest investigations on this matter concluded that ventilating at 70 breaths $\cdot \mathrm{min}^{-1}$ maximized MVV [14]. A later study utilized an $f_{\mathrm{R}}$ range of $60-120$ breaths $\cdot \mathrm{min}^{-1}$ [15] while another argued against accepting results obtained with a frequency of less than 65 breaths $\cdot \min ^{-1}$ [16]. A third investigation suggested a narrower window of $70-110$ breaths $\min ^{-1}$ [17]. The American Thoracic Society/European Respiratory Society (ATS/ERS) Task Force offered perhaps the most widely accepted range of $90-110$ breaths $\cdot \mathrm{min}^{-1}$ with an ideal rate of approximately 90 breaths. $\mathrm{min}^{-1}$, but also declared that no specific $f_{\mathrm{R}}$ can be mandated due to a lack of research on the topic [18].

The limited evidence supporting an ideal $f_{\mathrm{R}}$ range is problematic. Considering both the diagnostic and prognostic value of MVV, as well as its ability to assess participant compliance during pulmonary function testing [19], inaccurate results due to poor standardization may have substantial clinical implications. Consequently, it is imperative that the variety of current guidelines be evaluated. The aim of this investigation, therefore, was to determine whether there is an optimal $f_{\mathrm{R}}$ at which the MVV maneuver ought to be performed, i.e., to consistently provide the highest outcome value. This was accomplished by conducting MVV tests at a wide range of $f_{\mathrm{R}}$ utilizing a repeated-measures design. In addition to examining preselected $f_{\mathrm{R}}$, this study also explored the effect of a self-selected $f_{\mathrm{R}}\left(f_{\text {Rself }}\right)$. Given that synchronizing breathing frequency to a rhythm-keeping device at a preset rate may feel unnatural or interfere with performance, we hypothesized that participants would maximize MVV by ventilating at a $f_{\mathrm{R}}$ uniquely self-selected by each individual rather than breathing within a predetermined range.

\section{Methods}

\section{Study design}

Ten healthy, non-smoking adults (six men) were recruited from the University of California, Los Angeles (UCLA) community to participate in this study. Nine were undergraduate students aged 18-22 years old and one was a 46 year-old university employee (height $1.72 \pm 0.13 \mathrm{~m}$; mass $67.1 \pm 16.3 \mathrm{~kg}$ ). The UCLA Institutional Review Board approved this study, and all participants provided informed consent prior to enrollment.

Each participant performed MVV maneuvers using nine different preselected $f_{\mathrm{R}} \mathrm{S}$ ranging from 50 to 130 breaths $\cdot \mathrm{min}^{-1}$ in increments of 10 breaths $\cdot \mathrm{min}^{-1}$ as measured by a metronome. Additionally, all participants performed a maneuver using $f_{\text {Rself. In this condition, }}$ subjects performed the test without the aid of a metronome, and were instead instructed to breathe as rapidly and deeply as possible without inducing significant discomfort. The resulting frequency was then recorded. For each frequency, including $f_{\text {Rself, }}$ participants performed three trials for a total of 30 tests (10 per day with 2-min rest between each) over three consecutive days to allow for adequate recovery. To limit order and practice effects, a random number generator determined the sequence in which $f_{\mathrm{R}}$ was tested for each participant.

\section{Data acquisition}

All data were obtained using a metabolic measurement system (Oxycon Pro ${ }^{\mathrm{Tm}}$; CareFusion, Yorba Linda, CA) that underwent volume and gas composition calibrations prior to each testing session. All tests occurred in a laboratory setting where the ambient temperature and humidity were measured and entered into the system before calibration. The volume calibration was done mechanically with known volumes of air, while the composition calibration was performed using ambient air and a gas tank of $16 \% \mathrm{O} 2,4 \% \mathrm{CO} 2$ to encompass the 
range found in normal exhaled air. Participants were seated upright in a stationary chair, wore a nose clip, and breathed through a mouthpiece that connected to the metabolic cart. Participants were also instructed to refrain from eating or engaging in vigorous exercise at least before testing.

Prior to performing the first MVV maneuver, slow vital capacity (SVC) was measured using the same system. Participants were instructed to inhale as much air as possible in a single breath and then exhale, completely emptying the lungs. This value was obtained to compare the ratio of the tidal volume $\left(\mathrm{V}_{\mathrm{T}}\right)$ during $\mathrm{MVV}$ to SVC. In addition, participants took normal breaths to establish a baseline respiratory exchange ratio, which was used as a metabolic indicator to determine when a participant had achieved sufficient rest between trials. Once this value had been established, MVV testing began. For each trial, participants were instructed to maximize ventilation by inhaling and exhaling as deeply as possible for $12 \mathrm{~s}$. As frequent vigorous respiration can cause dry mouth, water was provided if requested between tests. During trials defined by a preselected $f_{\mathrm{R}}$, participants listened to a corresponding preset tempo from a metronome and timed their breaths accordingly. In between each beat, both an inhalation and an exhalation were performed. During the trials associated with $f_{\text {Rself }}$, no metronome was used- participants freely maximized breathing while the metabolic cart recorded $f_{R}$, the value of which was blinded until after a maneuver was completed. In addition to $f_{\mathrm{R}}$ and $\mathrm{MVV}$, which were recorded and analyzed for all trials, breath-by-breath measurements of $\mathrm{V}_{\mathrm{T}}$ and partial pressure of end-tidal
$\mathrm{CO}_{2}\left(\mathrm{PETCO}_{2}\right)$ were also obtained for all maneuvers except those at the preselected $f_{\mathrm{R}}$ of 130 breaths. $\mathrm{min}^{-1}$ $\left(f_{\mathrm{R} 130}\right)$ (Table 1).

\section{Statistical analysis}

Data for each subject were scaled relative to the maximum value recorded during preselected $f_{\mathrm{R}}$ and reported as the mean \pm standard deviation (SD) for all variables. Sample size was estimated from a combination of pilot testing and preliminary power calculations based on an alpha level of 0.05 and a beta level of 0.20 [20]. As suggested by the ATS/ERS Task Force [18], only the test that resulted in the highest MVV out of the three trials per $f_{\mathrm{R}}$ was used for data analysis. The overall effect of $f_{\mathrm{R}}$ was tested using repeated-measures analysis of variance (ANOVA); comparisons were made between the outcome value at every $f_{\mathrm{R}}$ and the maximum value using paired $t$-tests. The average MVV values were found across subjects for each $f_{\mathrm{R}}$, and the relationship between these values and the corresponding $f_{\mathrm{R}}$ and $\mathrm{V}_{\mathrm{T}}$ were analyzed using polynomial regression. The statistics were calculated in MATLAB (version 8.6.0; MathWorks, Inc., Natick, MA) and significance was determined using an alpha level of 0.05 .

\section{Results}

All ten participants successfully performed three trials at all ten $f_{\mathrm{R}}$ values. As demonstrated in Fig. 1, a third-order polynomial regression analysis showed that $\mathrm{MVV}=-0.0001\left(f_{\mathrm{R}}\right)^{3}+0.0258\left(f_{\mathrm{R}}\right)^{2}-1.38\left(f_{\mathrm{R}}\right)+96.9$ at preselected $f_{\mathrm{R}}$ and increased up to approximately 100 breaths $\min ^{-1}\left(\mathrm{r}^{2}=0.982, P<0.001\right)$. A paired $t$-test

Table 1 Outcome variables (scaled and absolute values)

\begin{tabular}{|c|c|c|c|c|c|}
\hline \multirow{2}{*}{$\begin{array}{l}f_{R} \\
\left(\text { breaths } \cdot \mathrm{min}^{-1} \text { ) }\right.\end{array}$} & \multicolumn{2}{|l|}{ MW } & \multicolumn{2}{|l|}{$\mathrm{V}_{\mathrm{T}}$} & \multirow{2}{*}{$\begin{array}{l}\mathrm{P}_{\mathrm{ET}} \mathrm{CO}_{2} \\
(\mathrm{mmHg})\end{array}$} \\
\hline & $(\%)$ & $\left(L \cdot \min ^{-1}\right)$ & $(\%)$ & $(\mathrm{L})$ & \\
\hline 50 & $76.2 \pm 9.9^{* \dagger}$ & $125.1 \pm 45.3$ & $99.1 \pm 1.6$ & $2.4 \pm 0.9$ & $15.3 \pm 2.0$ \\
\hline 60 & $81.7 \pm 13.9^{\dagger}$ & $131.4 \pm 52.0$ & $88.4 \pm 9.0^{\dagger}$ & $2.2 \pm 0.8$ & $15.0 \pm 3.3$ \\
\hline 70 & $84.3 \pm 11.9^{\dagger}$ & $134.1 \pm 47.2$ & $78.5 \pm 5.4^{\dagger}$ & $1.9 \pm 0.7$ & $14.5 \pm 2.9$ \\
\hline 80 & $87.5 \pm 8.3^{\dagger}$ & $139.4 \pm 50.2$ & $72.1 \pm 12.3^{*+}$ & $1.7 \pm 0.6$ & $14.2 \pm 2.7$ \\
\hline 90 & $91.4 \pm 5.9^{\dagger}$ & $144.1 \pm 49.6$ & $67.7 \pm 11.5^{*+}$ & $1.6 \pm 0.5$ & $13.3 \pm 2.1$ \\
\hline 100 & $93.3 \pm 3.7^{\dagger}$ & $147.6 \pm 51.5$ & $62.0 \pm 10.4^{* \dagger}$ & $1.5 \pm 0.5^{\dagger}$ & $14.2 \pm 2.7$ \\
\hline 110 & $92.2 \pm 9.5^{\dagger}$ & $144.9 \pm 48.4$ & $51.9 \pm 19.9^{*+}$ & $1.3 \pm 0.6$ & $13.6 \pm 2.2$ \\
\hline 120 & $90.2 \pm 10.2^{\dagger}$ & $144.7 \pm 58.3$ & $50.5 \pm 10.3^{*+}$ & $1.2 \pm 0.5$ & $13.0 \pm 2.4$ \\
\hline 130 & $81.0 \pm 11.4^{\dagger}$ & $129.6 \pm 52.1$ & $\mathrm{n} / \mathrm{a}^{\mathrm{b}}$ & $\mathrm{n} / \mathrm{a}^{\mathrm{b}}$ & $\mathrm{n} / \mathrm{a}^{\mathrm{b}}$ \\
\hline Self-Selected $(69.9 \pm 22.3)$ & $91.1 \pm 16.5$ & $144.8 \pm 59.4$ & $90.9 \pm 19.1$ & $2.1 \pm 0.7$ & $13.7 \pm 2.0$ \\
\hline Maximum $^{a}$ & - & $157.7 \pm 52.5$ & - & $2.4 \pm 0.9$ & $17.1 \pm 2.5$ \\
\hline
\end{tabular}

Values are presented as mean \pm SD both 1) scaled as a percentage of the maximum and 2) absolute. Statistical analysis was performed only on scaled values All values are reported as the percent of the maximum value obtained using preselected $f_{\mathrm{R}}$ values

Abbreviations: $f_{R}$ breathing frequency, $M V V$ maximum voluntary ventilation, $V_{T}$ tidal volume, $P E T C O_{2}$ partial pressure of end-tidal $C O 2$

${ }^{*} P<0.05$ when compared to self-selected $f_{\mathrm{R}}$

$+P<0.05$ when compared to maximum

a Highest value obtained across all $f_{\mathrm{R}}$ values for every participant

${ }^{b}$ Values were missing from data collection 


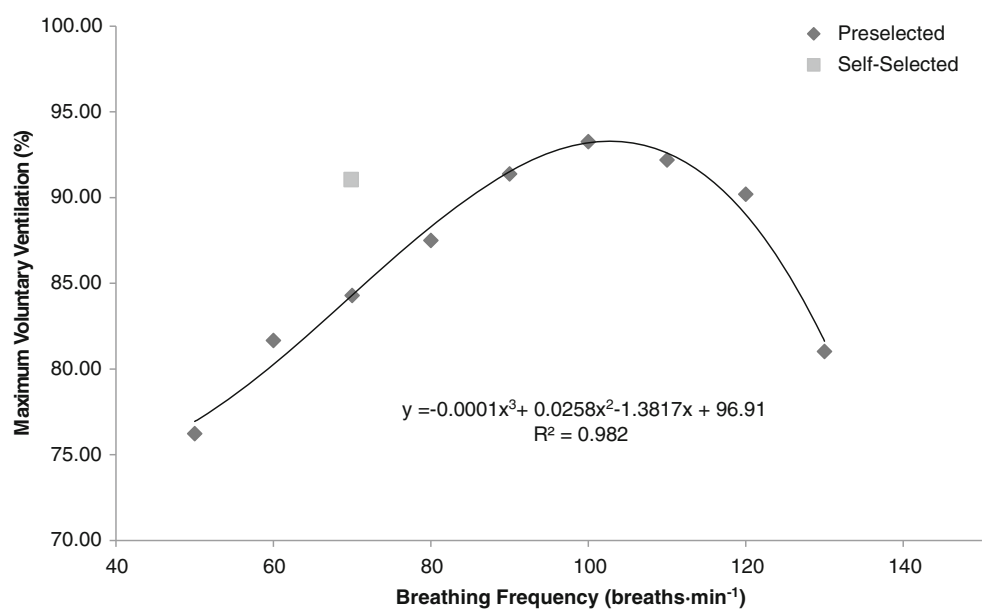

Fig. 1 Relationship between the average maximum voluntary ventilation (MW) across subjects and average breathing frequency (fR). MW values are presented as a percentage (\%) of the maximum. A polynomial regression analysis of the preselected fRs yielded a third-order relationship $\left(R^{2}=0.982, P<0.001\right)$

revealed that the MVV value obtained at an average $f_{\text {Rself }}$ of $69.9 \pm 22.3$ breaths $\cdot \min ^{-1}(91.1 \pm 16.5 \%$ of maximum) was not significantly different from the value measured at the roughly equivalent preselected $f_{\mathrm{R} 70}(84.3 \pm 11.9 \%$ of maximum; $95 \%$ confidence interval of difference: $(-2.7$, $16.3 \%), P=0.190)$. When the MVV values at all $f_{\mathrm{R}}$ values were compared to the average maximum value for all subjects, a repeated-measures ANOVA showed a significant effect of $f_{\mathrm{R}}$ on MVV $(P<0.001)$. Further statistical analysis showed that results obtained at every preselected $f_{\mathrm{R}}$ were significantly lower than this maximum value, but those measured at $f_{\text {Rself }}$ were not (Table 1). If multiple comparisons are controlled for using a Bonferroni correction, all preselected $f_{\mathrm{R}}$ values other than $f_{\mathrm{R} 110}$ and $f_{\mathrm{R} 120}$ remain significantly different from the maximum.

As demonstrated in Fig. 2, a linear regression analysis revealed that $\mathrm{V}_{\mathrm{T}}=-2.63(\mathrm{MVV})+300.4$ at preselected $f_{\mathrm{R}}$ $\left(\mathrm{r}^{2}=0.846, P<0.001\right)$. This steadily decreasing trend in $\mathrm{V}_{\mathrm{T}}$ was observed as the preselected $f_{\mathrm{R}}$ and $\mathrm{MVV}$

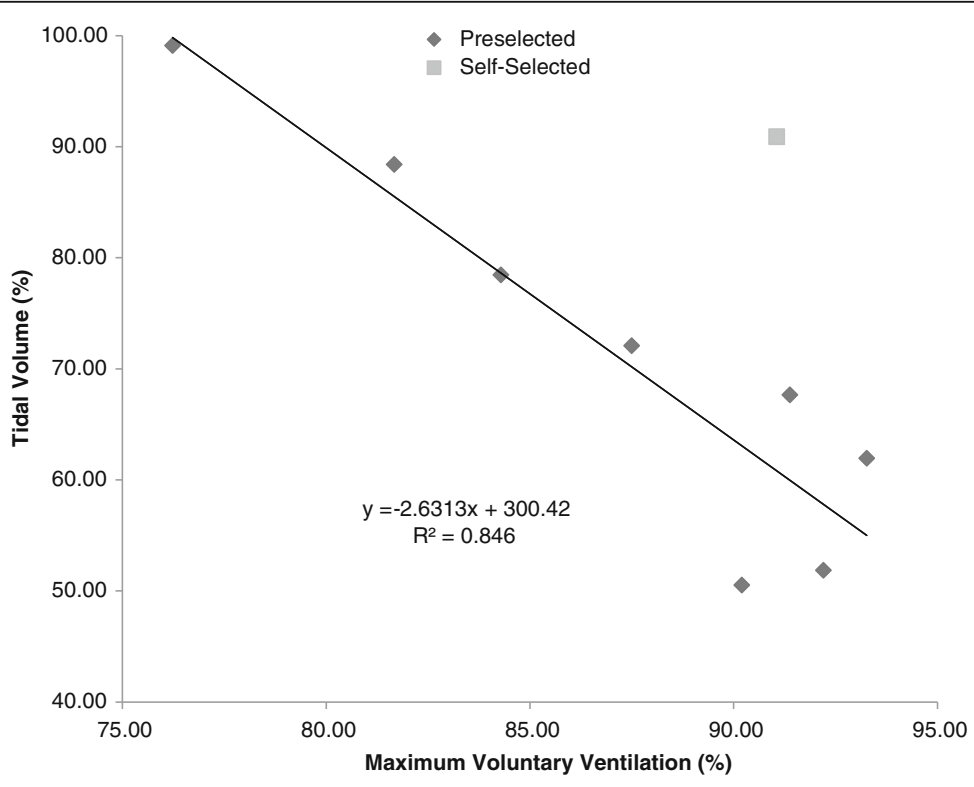

Fig. 2 Relationship between the average tidal volume $\left(V_{T}\right)$ across subjects and the average maximum voluntary ventilation $(M W) . V_{T}$ and $M W$ values are presented as a percentage (\%) of their respective maxima. A linear regression analysis revealed a significant decreasing trend for the preselected breathing frequencies $\left(R^{2}=0.846, P<0.001\right)$ 
increased, but paired $t$-tests showed that this inverse relationship did not remain true for $f_{\text {Rself }}$. The $\mathrm{V}_{\mathrm{T}}$ obtained at this $f_{\mathrm{R}}(90.9 \pm 19.1 \%$ of maximum) was significantly greater than the $\mathrm{V}_{\mathrm{T}}$ associated with the most similar MVV value (at $f_{\mathrm{R} 100}, 62.0 \pm 10.4 \%$ of maximum; $95 \%$ confidence interval of difference: (17.5, 40.4\%), $P<0.001)$. By contrast, none of the $\mathrm{PETCO}_{2}$ data measured at the preselected $f_{\mathrm{R}}$ differed significantly from that of $f_{\text {Rself }}$, and all were significantly less than the average $\mathrm{PETCO}_{2}$ maximum.

\section{Discussion}

Our study, to the best of our knowledge, is the first that examines the effect of altering $f_{\mathrm{R}}$ on MVV. After testing preselected $f_{\mathrm{R}}$ values ranging from 50 to 130 breaths. $\mathrm{min}^{-1}$ as dictated by a metronome and one self-selected $f_{\mathrm{R}}$ by each participant, we found that trials conducted at $90-120$ breaths. $\mathrm{min}^{-1}$, and the self-selected rate were equally successful at maximizing MVV. This result differed from our hypothesis where we predicted that only $f_{\text {Rself }}$ would yield the highest MVV. When compared to the aforementioned guidelines for optimizing MVV of 60-120, 70-110, and 90-110 breaths. $\mathrm{min}^{-1}$ suggested by Dillard et al. (1993) [15], Morris (1976) [17], and the ATS/ ERS Task Force [18] respectively, our findings disagreed with the first and second recommendations but closely resembled the third. However, our data do not support the ATS/ERS Task Force's recommended goal of 90 breaths $\cdot \mathrm{min}^{-1}$. Considering that participants maximized MVV by breathing at $f_{\mathrm{R} 90-120}$ and $f_{\text {Rself }}$, we recommend choosing either of these approaches rather than aiming for a single value of $f_{\mathrm{R}}$. Furthermore, because maximal values were obtained at $f_{\text {Rself, }}$ our data suggest that no rhythm-keeping instrument or preselected $f_{\mathrm{R}}$ range may be necessary at all.

Interestingly, while the trials defined by a $f_{\mathrm{R} 70}$ yielded a significantly lower MVV than the mean maximum for all subjects, they were not statistically different than the MVV value obtained at $f_{\text {Rself }}\left(69.9 \pm 22.3\right.$ breaths $\cdot \mathrm{min}^{-1}$, nearly equivalent to 70 breaths $\left.\cdot \mathrm{min}^{-1}\right)$. This is likely explained by the variance, which suggests that while breathing at a self-selected rate may increase the likelihood of achieving one's true MVV, this chosen rate may not be equal among all individuals. Another noteworthy observation stemmed from the differences in $V_{T}$ measured at the preselected and self-selected $f_{\mathrm{R}}$. When plotted against MVV, $\mathrm{V}_{\mathrm{T}}$ steadily decreased at the preselected $f_{\mathrm{R}}$ values. This was unsurprising considering that MVV values were greater at higher $f_{\mathrm{R}}$ and as $f_{\mathrm{R}}$ increases, the tidal volume may decrease in order to sustain the faster rate. However, it is also possible that during exercise, increased intra-thoracic pressure and work of breathing can permit concomitant increases in $f_{\mathrm{R}}$ and $\mathrm{V}_{\mathrm{T}}$. Interestingly, the data showed that the $\mathrm{V}_{\mathrm{T}}$ associated with the MVV value obtained at $f_{\text {Rself }}$ deviated from the trend observed at the preselected $f_{\mathrm{R}}$ values-it was significantly greater than its most similar preselected counterpart (obtained at $f_{\mathrm{R} 100}$ ). This suggests that when breathing at a self-selected rate, individuals are more likely to utilize an optimal combination of slower deep breaths and faster shallower breaths to maximize MVV. Additionally, matching the rate of one's breathing to a metronome or other rhythm-keeping instrument can feel distracting and unnatural to the participant, especially compared to ventilating at a natural rate during an assessment of $\dot{V}_{\text {Emax }}$, which may decrease the likelihood of an accurate measurement $[1,21]$.

Unlike MVV and $\mathrm{V}_{\mathrm{T}}$, there were no significant relationships observed between $f_{\mathrm{R}}$ and $\mathrm{PETCO}_{2}$. This is somewhat unexpected as $\mathrm{PETCO}_{2}$ is known to decrease as the ventilation increases. The lack of this trend in the data may be partially explained by the missing values associated with $f_{\mathrm{R} 130}$. It also is plausible that the inverse relationship between $f_{\mathrm{R}}$ and $\mathrm{PETCO}_{2}$ is not evident until the rate of ventilation is much greater than what was tested in this study. Moreover, it is important to note that the missing values for $\mathrm{V}_{\mathrm{T}}$ at $f_{\mathrm{R} 130}$ may not have fit the strong, negative linear correlation demonstrated in Fig. 2. Due to the sharp decrease in MVV from $f_{\mathrm{R} 120}$ to $f_{\mathrm{R} 130}$, it is unlikely that the corresponding reduction in $\mathrm{V}_{\mathrm{T}}$ would have been of the same magnitude; however, it is also improbable that this single data pair would have rendered the aforementioned relationship between $V_{T}$ and MVV non-significant.

Regarded as one of the most long-standing PFTs, equations developed to predict MVV from more widely applicable parameters, such as FEV, have existed since the mid-twentieth century. The most common and simplistic of these include $\mathrm{MVV}=\mathrm{FEV}_{1} \times 35$ [22]; $\mathrm{FEV}_{1} \times 37.5$ [23]; and $\mathrm{FEV}_{1} \times 40$ [24]. And while some still prefer to utilize these equations over a direct assessment, substantial evidence has highlighted the limitations of such practice. These along with many similar reference equations fail to account for a number of physical characteristics that have been shown to influence MVV. The most predominant of these include height, sex, and age $[25,26]$. Studies have shown that individuals who smoke [27], suffer from cystic fibrosis [28], and women who are pregnant [29] also exhibit MVV values that deviate from height-, sex- and age-matched controls. Furthermore, a growing body of literature suggests that current reference equations for MVV and other PFTs fail to account for ethnic and socioeconomic disparities in addition to ignoring the trend of increasing racial diversity [30, 31]. Investigations have derived specific prediction equations based on ethnicity, such as in Brazilian [11], Chinese [13], Filipino [32], and African-American adolescent [12] populations, but all possess significant mathematical 
differences from one another. The recurring shortcoming of these equations is their lack of cohesion-no comprehensive equation exists that successfully incorporates all of the aforementioned variables. As a result, a number of studies have argued that MVV is best measured directly $[19,28,33]$.

It is important to note that the results from this investigation possess similar limitations to those outlined above, including a homogenous participant cohort and the inability to account for differences in physical characteristics due to a small sample size. Further research ought to examine whether a self-selected $f_{\mathrm{R}}$ is as accurate and more efficient than a preselected range of $f_{\mathrm{R}}$ in a larger, more heterogeneous population. Future investigations should also explore other methods to standardize the assessment of MVV, for instance, an optimal test duration and the feasibility of a definitive reference equation. Until then, we advise that participants perform the maneuver preferably at a self-selected $f_{\mathrm{R}}$ or within a preselected range of $90-120$ breaths $\mathrm{min}^{-1}$.

\section{Conclusion}

Although not as prominent as in decades past, MVV remains a clinically relevant PFT whose outcomes are valuable in cardiopulmonary exercise testing and aid in the diagnosis of various neuromuscular, cardiovascular, and pulmonary diseases. This study demonstrates the shortcomings of the current lack of standardization in MVV testing and establishes data-driven recommendations for optimal $f_{\mathrm{R}}$. While classic literature has previously investigated this topic, the antiquity of these works warrants modern research. Furthermore, what these studies suggest as an optimal measurement technique has been overlooked or forgotten in the current guidelines. Our paper therefore contributes a new and much-needed focus on an evidence-based approach to selecting the optimal $f_{\mathrm{R}}$ for MVV measurement. We recommend that participants perform an MVV maneuver at a self-selected $f_{\mathrm{R}}$ as it maximizes the likelihood of an accurate measurement by optimizing a combination of slower deep breaths and faster shallower breaths, eliminates the necessity to synchronize breaths to a rhythm-keeping device, and more closely resembles the procedure to obtain $\dot{V}_{\text {Emax }}$. If an individual is unable to perform or performs the maneuver poorly at a self-selected $f_{\mathrm{R}}$, ventilating within a mandated $f_{\mathrm{R}}$ range of $110-120$ breaths $\min ^{-1}$ may also be acceptable.

\section{Abbreviations}

ATS/ERS: American Thoracic Society/European Respiratory Society; $\mathrm{FEV}_{1}$ : Forced expiratory volume in $1 \mathrm{~s}_{i} F_{\mathrm{R}}$ : Breathing frequency; $f_{\mathrm{Rsel}}$ : Selfselected breathing frequency; $f_{\mathrm{RX}}$ : Preselected breathing frequency of $X$ breaths. $\mathrm{min}^{-1} ; \mathrm{MW}$ : Maximum voluntary ventilation; $\mathrm{PETCO}_{2}$ : Partial pressure of end-tidal $\mathrm{CO}_{2} ; \mathrm{PFT}$ : Pulmonary function test; SD: Standard deviation; SVC: Slow vital capacity; UCLA: University of California, Los Angeles;

$\dot{V}_{\text {Emax }}$ : Maximal exercise ventilation; $\mathrm{V}_{\mathrm{T}}$ : Tidal volume

\section{Acknowledgements}

We would like to express our gratitude to Andrew Chang and Jonathan Lee for their assistance with data collection.

\section{Availability of data and materials}

The data that support the findings of this study are available from the corresponding author upon reasonable request.

\section{Authors' contributions}

All authors made substantial contributions to this study and manuscript. The study was conceived and designed by BAD and CBC. EVN and WS collected and analyzed the data. EVN, BAD, WS, and CBC composed significant portions of the manuscript and made crucial edits. All authors also read and approved the final version of the manuscript.

Ethics approval and consent to participate

This study was approved by the UCLA Institutional Review Board. All participants provided informed consent prior to enrollment.

\section{Competing interests}

The authors declare that they have no competing interests.

\section{Publisher's Note}

Springer Nature remains neutral with regard to jurisdictional claims in published maps and institutional affiliations.

\section{Author details}

${ }^{1}$ Exercise Physiology Research Laboratory, Departments of Medicine and Physiology, David Geffen School of Medicine at UCLA, 10833 Le Conte Avenue, 37-131 CHS Building, Los Angeles, CA 90095, USA. ²Medical Imaging Informatics, Department of Radiology, David Geffen School of Medicine at UCLA, Los Angeles, CA, USA.

Received: 27 March 2017 Accepted: 14 May 2018

Published online: 24 May 2018

\section{References}

1. Mottram C. Ruppel's manual of pulmonary function testing. 11th ed. St. Louis: Elsevier Health Sciences; 2017. p. 66-67.

2. Braun NM, Arora NS, Rochester DF. Respiratory muscle and pulmonary function in polymyositis and other proximal myopathies. Thorax. 1983;38: 616-23.

3. Serisier DE, Mastaglia FL, Gibson GJ. Respiratory muscle function and ventilatory control. I in patients with motor neurone disease. II in patients with myotonic dystrophy. Q J Med. 1982;51:205-26.

4. Rochester DF, Esau SA. Assessment of ventilatory function in patients with neuromuscular disease. Clin Chest Med. 1994;15:751-63.

5. Bevacqua BK. Pre-operative pulmonary evaluation in the patient with suspected respiratory disease. Indian J Anaesth. 2015;59:542-9.

6. Singh VN. The role of gas analysis with exercise testing. Prim Care. 2001;28: 159-79. vii-viii

7. Ferrazza AM, Martolini D, Valli G, Palange P. Cardiopulmonary exercise testing in the functional and prognostic evaluation of patients with pulmonary diseases. Respiration. 2009;77:3-17.

8. Toma N, Bicescu G, Enache R, Dragoi R, Cinteza M. Cardiopulmonary exercise testing in differential diagnosis of dyspnea. Maedica (Buchar). 2010; 5:214-8.

9. Arena R, Sietsema KE. Cardiopulmonary exercise testing in the clinical evaluation of patients with heart and lung disease. Circulation. 2011;123: $668-80$.

10. Myers J. Applications of cardiopulmonary exercise testing in the management of cardiovascular and pulmonary disease. Int I Sports Med. 2005;26(Suppl 1):S49-55.

11. Neder JA, Andreoni S, Lerario MC, Nery LE. Reference values for lung function tests. II. Maximal respiratory pressures and voluntary ventilation. Braz J Med Biol Res. 1999;32:719-27.

12. Fulton JE, Pivarnik JM, Taylor WC, Snider SA, Tate AL, Frankowski RF. Prediction of maximum voluntary ventilation (MW) in African-American adolescent girls. Pediatr Pulmonol. 1995;20:225-33.

13. Kor AC, Ong KC, Earnest A, Wang YT. Prediction of the maximal voluntary ventilation in healthy adult Chinese subjects. Respirology. 2004;9:76-80. 
14. Bernstein L, D'Silva JL, Mendel $D$. The effect of the rate of breathing on the maximum breathing capacity determined with a new spirometer. Thorax. 1952;7:255-62

15. Dillard TA, Hnatiuk OW, McCumber TR. Maximum voluntary ventilation. Spirometric determinants in chronic obstructive pulmonary disease patients and normal subjects. Am Rev Respir Dis. 1993;147:870-5.

16. Miller WF, Johnson RL Jr, Wu N. Relationships between maximal breathing capacity and timed expiratory capacities. J Appl Physiol. 1959;14:510-6.

17. Morris JF. Spirometry in the evaluation of pulmonary function. West J Med. 1976;125:110-8.

18. Miller MR, Hankinson J, Brusasco V, Burgos F, Casaburi R, Coates A, Crapo R, Enright P, van der Grinten CP, Gustafsson P, et al. Standardisation of spirometry. Eur Respir J. 2005;26:319-38.

19. Campbell SCA. Comparison of the maximum voluntary ventilation with the forced expiratory volume in one second: an assessment of subject cooperation. J Occup Med. 1982;24:531-3.

20. Dupont WD, Plummer WD Jr. Power and sample size calculations. A review and computer program. Control Clin Trials. 1990;11:116-28.

21. Johnson BD, Weisman IM, Zeballos RJ, Beck KC. Emerging concepts in the evaluation of ventilatory limitation during exercise: the exercise tidal flowvolume loop. Chest. 1999;1 16:488-503.

22. Clark TJ, Freedman S, Campbell EJ, Winn RR. The ventilatory capacity of patients with chronic airways obstruction. Clin Sci. 1969;36:307-16.

23. Burrows B, Strauss RH, Niden AH. Chronic obstructive lung disease 1, 2: III. Interrelationships of pulmonary function data. Am Rev Respir Dis. 1965;91: 861-8.

24. Jones $\mathrm{NL}$, Jones $\mathrm{G}$, Edwards RH. Exercise tolerance in chronic airway obstruction. Am Rev Respir Dis. 1971;103:477-91.

25. Cherniack RM, Raber MB. Normal standards for ventilatory function using an automated wedge spirometer. Am Rev Respir Dis. 1972;106:38-46.

26. Bass $\mathrm{H}$. The flow volume loop: normal standards and abnormalities in chronic obstructive pulmonary disease. Chest. 1973;63:171-6.

27. Hasan S, Rakkah NIAV, Attaur-Rasool S. Effect of smoking on respiratory pressures and lung volumes in young adults. Biomedica. 2013;29:96-100

28. Stein R, Selvadurai H, Coates A, Wilkes DL, Schneiderman-Walker J, Corey M. Determination of maximal voluntary ventilation in children with cystic fibrosis. Pediatr Pulmonol. 2003:35:467-71.

29. Tell A, Bagali S, Aithala M, Khodnapur J, Dhanakshirur GB. Alterations in minute ventilation, maximum voluntary ventilation and dyspneic index in different trimesters of pregnancy. Indian J Physiol Pharmacol. 2014;58:96-9.

30. Ortega VE, Kumar R. The effect of ancestry and genetic variation on lung function predictions: What is "normal" lung function in diverse human populations? Curr Allergy Asthma Rep. 2015;15:16.

31. Duong M, Islam S, Rangarajan S, Teo K, O'Byrne PM, Schunemann HJ, Igumbor E, Chifamba J, Liu L, Li W, et al. Global differences in lung function by region (PURE): an international, community-based prospective study. Lancet Respir Med. 2013;1:599-609.

32. Roa Jr CC, Zaldivar CA, Salonga R, Bobadilla J, Lansang MA, Reodica R, Balgos A, Blanco J, TJ Q. Normal standards for ventilatory function test in adult Filipinos. Philipp J Intern Med. 2013;51:1-6.

33. Pellegrino R, Viegi G, Brusasco V, Crapo RO, Burgos F, Casaburi R, Coates A, van der Grinten CP, Gustafsson P. Hankinson J, et al. Interpretative strategies for lung function tests. Eur Respir J. 2005;26:948-68.

\section{Ready to submit your research? Choose BMC and benefit from:}

- fast, convenient online submission

- thorough peer review by experienced researchers in your field

- rapid publication on acceptance

- support for research data, including large and complex data types

- gold Open Access which fosters wider collaboration and increased citations

- maximum visibility for your research: over $100 \mathrm{M}$ website views per year

At BMC, research is always in progress.

Learn more biomedcentral.com/submissions 